\title{
Improving the Health Industry with Stock Management Techniques
}

\author{
Luis Henrique Machado Cerqueira, Edson José Dalto, Paulo Sérgio de Souza Coelho \\ Faculdades Ibmec, Brasil \\ \{luis.cerqueira, edalto, psergio\}@gmail.com
}

\begin{abstract}
Considering that the health industry has changed radically along the years, the efficient professional management of entities connected to this segment is fundamental. Modern techniques, such as demand forecast and stock management, contribute to a better management of scarce and critical resources which might put human lives at risk.

The present study describes the use of quantitative techniques for supply forecast and stock management of a blood bank from a given hospital. The demonstration of the viability of these techniques broke paradigms. Furthermore, it has fomented new studies with emphasis on improving procedures and rationalisation. It has also brought an improvement in terms of the institution operations, increasing the level of efficiency.
\end{abstract}

Key-words: Health business, Supply management, Forecasting, Logistics

\section{Introduction}

Every corporate sector has shown a great preoccupation with economical dynamics, where not only the resources are scarce, but also the management procedures. The procedures optimisation becomes a basic premise for survival. Companies seeking to maintain their competitiveness should generate an added value to their clients at the least possible cost. "To be competitive is to be able to overcome the direct competitors, where the performance is more valued: those highly sought market niches" [2]. Therefore, finding the overcoming paths is the great challenge for modern organisations.

In the health industry, the main motivating factor for this rationalisation, chiefly in our large metropolis, is the strong presence of major national and foreign groups. Those groups invest many resources in infrastructure and technical-administrative capacity [7]. A consequence of this change of scenario is the dissemination of MBA courses in health and graduation courses in hospital management. These courses are designed for professionals who need to acquire, or deepen their knowledge on health management [5]. Consequently, the present health institutions have perceived the necessity in acting in a more efficient way, and for that, there is a tendency to absorb intellectual capital with expertise in the health industry.

Focusing upon this environment, the main objective of this study is to show the benefits of employing quantitative techniques on blood demand forecasting, to support the logistic management of stocks in health institutions. Therefore, a study case was carried-out in a blood bank. The stocked units are Blood Components, obtained from blood in natura. Further to the blood collection, it's necessary to process the colleted blood as soon as possible, in order to have them stocked, since the Blood Components have better perishing indices than the whole blood. As each Blood component presents different perish ability and specific demands, the management of these stocks becomes an extremely complex process.

In accordance with the Art. 1 of the Brazilian Law 10205 of 21 st March, 2001, it is forbidden to purchase or sell any type of blood or its components, throughout the national territory, neither by individuals nor by commercial companies. Due to this legal restriction, it's fundamental to secure a good stock planning and a proper management of a blood donation campaign. On the other hand, it's important to consider that lack of supply for the market is a disastrous situation in the social point of view. Different from other business segments, a blood bank cannot present a 
scarcity of Blood Components, for most of times; the life of a human being depends on those components. In a clear administrative analysis, the management of the products in stock is fundamental for that life in particular.

Those elements, in terms of supply and demand, turned the stock management of a blood bank into an extremely critical business. This represents the main reason for the case study carried-out. There is no knowledge of any autonomous information system that is efficient in terms of supply and stock management, which deals with the particularities and characteristics of a blood bank. In general terms, those types of institutions need to develop their own systems. Even so, they habitually show a low level of automation, always depending on a human valuation to take basic operational decisions, such as the right moment to start a donation campaign.

The present study is structured in five different sections. In addition to this introduction, the second section describes the object of the study. The third brings us a revision of the literature on quantitative methods applied to demand prevision. Section four deals with application of management techniques of a blood bank. Finally the last one presents the conclusion.

\section{Object of the Study}

The modern management leads the companies to take their objectives beyond the traditional economical vision. The social issues, particularly, have become fundamental to be managed [1]. Likewise, the operational rate of efficiency has also become instrumental for the companies. Although there isn't a direct preoccupation with competitors, these institutions have a though mission in supplying an excellent service with very limited resources. Those characteristics are present at Santa Casa de Misericórdia, in Rio de Janeiro - Brazil. Santa Casa de Misericórdia is the chosen institution for the study. Inaugurated in 1582, Santa Casa is a renowned health institution that renders services to the "Sistema Único de Saúde" (Government Unified Public Health System). Their structure holds dozens of infirmaries, ambulatories for several medical specialities, including a blood bank, object of this study, with the capacity of 200 daily blood collections [11].

In terms of raw material availability, it's fundamental to identify the appropriate donation campaign to be carried-out for each stock historical moment. There are many possibilities, with different costs and results. For instance, the televised campaigns are more onerous than the radio broadcasted ones, and both present quite distinct results. For the efficient use of financial resources, it's fundamental to quantify both the demand of each Blood Component and, the natural availability to define the most appropriate type of campaign. Should it be more aggressive and onerous or less?

The quantitative methodology was adopted to analyse and shape that environment, based on historical data. The data referring to the stock in the system were considered, mainly the daily input and output of blood, to evaluate the tendency and seasoning of blood availability and the demand of Blood Components. That's how it was done to analyse the efficiency of various types of campaigns for blood collection.

\subsection{Products}

There are four types of Blood Components taken into account in this study: Packed red cells; Platelet Concentrate, Fresh Frozen Plasma and Factor VIII Cryoprecipitate. For production purposes, we call whole blood, the blood in natura i.e. the raw material for all blood components [10]. The total number of blood types is eight divided into four groups $(\mathrm{A}, \mathrm{B}, \mathrm{AB}$, and $\mathrm{O})$ and the Rhesus Factor, also known as Rh Factor, which can be either positive or negative.

Every Blood component needs to be identified in relation to the originating blood type. However, only the Packed Red Cells (Concentrates of Haemocytes) and Platelets need to go through the Rh identification. These details can be checked in. So there are, for instance, only four types of Plasma, but eight types of Packed Red Cells. Each Blood component has specific functions, appropriate for different needs, as well as a particular lifetime.

Source: Information supplied by Santa Casa's Blood Bank

\begin{tabular}{|l|l|l|l|}
\hline Product & Blood Type & Rh factor & Lifetime \\
\hline Packed Red Cells & 4 types & 2 types & 35 days \\
\hline Platelet Concentrate & 4 types & 2 types & 3 or 4 days \\
\hline Plasma & 4 types & Indifferent & 1 year \\
\hline Factor VIII Cryoprecipitate & 4 types & Indifferent & 1 year \\
\hline
\end{tabular}

Table 1 - List of Blood Components

Considering just the four components described on Table 1, with their own characteristics, we have a total of 24 items of stock. Each item, like the A negative
Packed Red Cells, represents the smallest stocking keeping unity also known as SKU [9]. 
Each SKU presents an absolutely independent demand, i.e. when the hospital sends a blood request, the doctors inform the required SKU to attend the patient needs. We have, then, configured a complex necessity of demand and stock management.

\subsection{Supply and Demand}

The demand of products from the institution is originated mainly by the Santa Casa hospital own patients. In some cases, product unities may be supplied to other hospitals, medical centres or even blood banks.

The supply of raw material, blood in natura, is formed by donations done by several members of the Brazilian civil society. Among these people, there is a permanent current of people who donate irrespective of campaigns known as regular blood donors. There are also occasional donors, encouraged by some intermittent stimulus. Two principal stimuli will be considered. First, the donation could occur through a personal request. That is, the recipient of Blood Components knows in advance that the patient will need blood transfusion, and is requested to get donors to replenish the stock. These are considered occasional donors. There is, on the other hand a variable current of people who donate encouraged by advertising campaigns.

The blood bank is responsible for the collection to guaranty the stock levels. The donations aren't automatically processed to generate the stock keeping units. Before this step is taken, there is a quality valuation procedure of the colleted material. Exams are carried-out, like serology, to detect any blood transmitted disease, such as AIDS, B Hepatitis, Chaga's Disease, etc. Therefore, only the donations with nopositive serology are processed and transformed into products.

To increase the efficiency and minimise the contamination risk, there is an initial clinical screening, where the prospective donor answers a detailed questionnaire. The main questions are related to the medical and behavioural history, of the individual.

If the initial selection doesn't reject the donor, the collection is carried-out. In this stage, the raw material is colleted, prior to the serology test. Another part is collected to be submitted to a number of tests, to check among other characteristics the Rh factor and blood type. Finally the largest quantity, an average of $400 \mathrm{ml}$, will be stocked, fractioned into Blood Components, and used later, in case of favourable laboratory tests. While the test results are not ready, the Blood Components are stored totally separated from the blood already approved by lab tests. At this time, the components are not considered free stock.

The blood bank of the institution in question prioritises the support of own patients. In general terms, are the surgical interventions that demand stock replenishment of lost blood during the process. The service begins with collection from the donor, blood handling until the transfusion process.
Other private and independent blood banks, obtain financial returns from the transfusion service. In general terms, these private institutions attend hospitals and medical centres, and render an essential service to the population. As the commercialisation of the raw material is forbidden, each patient is responsible for the necessary number of donors, and it's up to the institution to collect the raw material, process and store it, and proceed with the transfusion.

\section{Quantitative Methods Applied to the Management of Stocks Supply and Demand}

The management process is directly linked to the decision making. It can even be said that to manage is to take good and quickly decisions. The managing director decision process is defined in relation to the organisation he manages, which is a complex environment. The decision processes within complexes scenarios requires a deeper analysis of the possible alternatives [6].

The decision becomes particularly critical when it depends on a forecast. It occurs with high frequency during the Management Operations [3]. That criticality arises from the so called decisive inertia, represented by the gap between the decision taking and its effectuation, which only occurs after the resources procedure is done. Therefore, the decision maker needs to anticipate himself to the future necessity, so, the decision may be taken considering the specific inertial period, avoiding losses during the operation.

Considering the problem of prevision, several methodologies are available. The classic division between the quantitative and qualitative methodologies is more detailed in the scheme proposed by Corrêa \& Corrêa shown in Illustration 1.

The techniques of qualitative previsions are of recognised importance, mainly in scenarios where the information isn't structured, like the cases of difficult quantification. In general terms, it's considered that both techniques, qualitative and quantitative are complimentary.

The quantitative techniques are subdivided in Intrinsic and Extrinsic [3]. This distinction is done by virtue of the information source used by the technique to do the forecasting. When just the observations of the variable that is under study are used in the composition of the prevision model, this technique is known as Intrinsic. It's the case of classic models of temporal series. As for the extrinsic techniques, they use other variables in the construction of the prevision model, such as the multiple or simple regression. The linear models are more used estimated through minimum squares method. 
Source: Adapted from Corrêa e Corrêa [3]

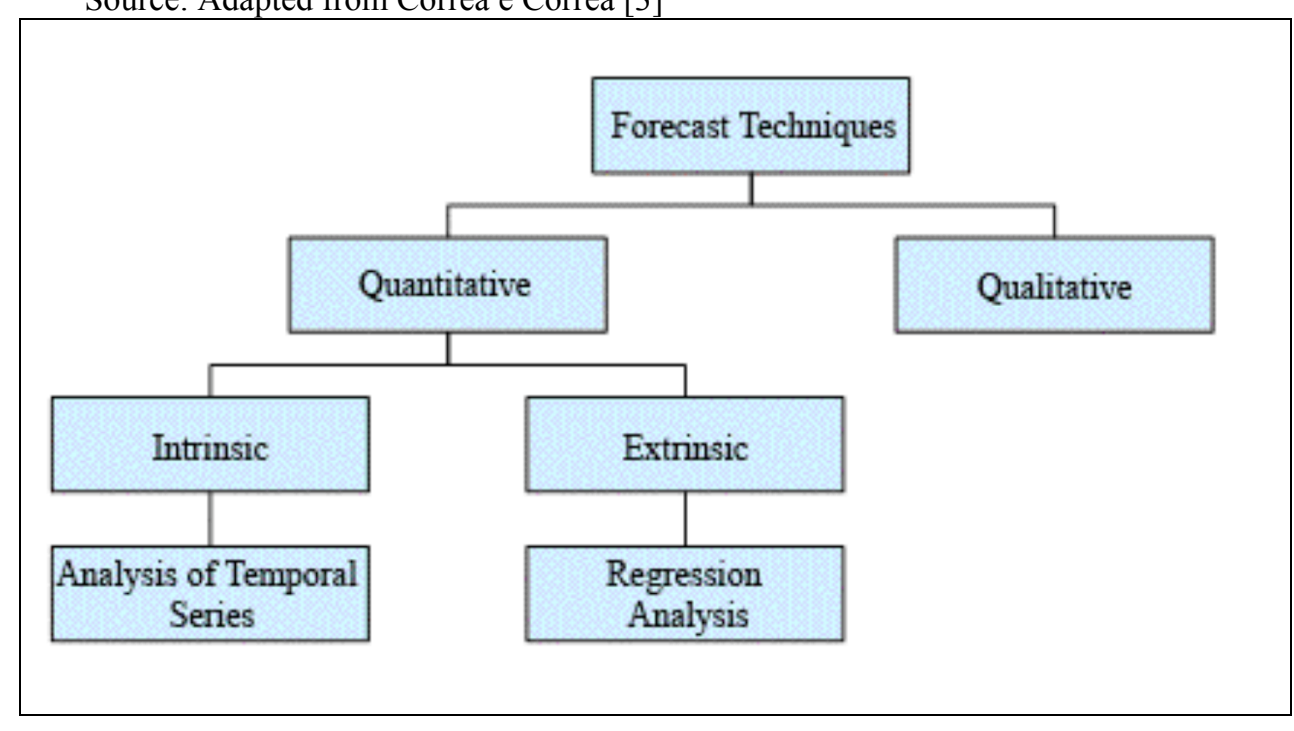

Illustration 1 - Prevision Methods

For instance, in the demand prevision for Blood Components, one can do analysis that considers only the historical data on the demand. This is an analysis of temporal series, therefore intrinsic, and it could include temporal information to identify tendency or seasonality. If on the other hand, external information such as data related to automobile accidents were used in that analysis, the technique becomes extrinsic.

Quantitative prevision techniques are part of an important branch of the Operational Research. A more complete reference for the study of temporal series is found in Winston \& Albright [14], for the regression analysis, in Mendenhall \& Sincich [8], Sincich [13] and Draper \& Smith [4].

The techniques based on temporal series aim at reproducing past behavioural standards in the values to be previewed. The most used ones for this purpose are the Moving Average and Exponential Adjustment. Other techniques, like classical decomposition and the Holt-Winters, assimilate tendency and seasonable factors in the prevision.

The regression analysis is divided into simple and multiple due to the number of involved explainable variables. The technique consists on estimating the mathematical expression that lists the explanatory variables. The Minimum Squared Method initially stipulates the relationship expression form and determines through optimisation, the equation coefficients, commonly called parameters or betas. The expressions are quite simple when an only explanatory variable is used. However, when the regression is multiple, these expressions take over more complex forms.

\section{Stock Management}

This is a daily crucial point of any company and requires an extra attention from the managers. In blood banks, above all, the raw material management and its blood components require a lot of planning, since the scarcity may jeopardise the health of patients. On the other hand, its collection is not a simple purchase and production process; instead, it's something that requires time, and many times the good will of the civil society. The replenishing time is normally long; therefore, it must be done well in advance.

The main factors that undermine the stock planning are the uncertainties in relation to the blood quantity donated along the time, as well as the demand of blood components in blood banks. Another critical factor that hampers the managing director's job is linked to blood components lifetime that varies from three days to one year. For that reason it's not feasible to store large quantities of blood packs, establishing, this way, a safety stock capable of attending any demand. On the other hand, due to the importance of this raw material, there cannot be any shortage of the product upon demand.

Models like the replenishing point and economic lot can be applied in a blood bank, while the balance of blood components is been reduced to the quantity defined as point of replenishing, the administrator takes the initiative of requesting an economic lot size. This process should be done through a trigger in the information system that controls the stock and goes off in the instance the quantities reach the established critical point.

It's also part of the blood bank manager's daily routine: to be aware of the demand's behaviour, to grasp 
what type of action affects its behaviour and, finally to know how to interpret the different scenarios.

\subsection{Database}

For this study were used historical data related to the supply of whole blood and to the demand of 24 SKU's of a blood bank in the scope of 304 days - January to October, 2004. The whole blood input information and the output of each product were obtained directly from blood bank, according to their records. In the extraction was also identified the quantity of donations rejected due to failed serology tests.

\subsection{Supply Management}

The supply management is instrumental for stock maintenance. The supply of whole blood is done exclusively through donations. The volume of donations may be stimulated by two different ways, making up the total supply. On a fixed level originated by the regular donor and, on a sporadic level originated by the occasional donor.

The regular donor is officially registered in the blood bank, and may be directly reached usually by telephone or e-mail. There is a minimum interval time between blood donations done by the same person: males every 2 months, up to 4 times a year and females every 3 months, up to 3 times a year. This regularity makes up the fixed level of the whole blood supply. The occasional donor may be reached through the use of public campaigns. This fraction of supply makes up the sporadic volume of raw material in a blood bank. The control of this fraction is fundamental in terms of product stock management, once the total process is lengthy. From the decision of campaign launching to the whole blood collection there is an elapse of a few days that can be critical for the blood stock. Naturally, the stimulus to increase the supply has to be done according to the demand that has been checked, and the one that is previewed for the days ahead.

As a fundamental starting point for the supply analysis, it was studied the donation efficiency, which was defined according to the total volume of blood released after the serology test vis-à-vis the total obtained. The level of efficiency is defined through a loss percentage rate, calculated by the expression:

$$
1-\left(\frac{\text { Quantity of packs released }}{\text { Quantity of packs collected }}\right) \times 100
$$

The above equation represents the historic series of the efficiency level. As the level shows the loss percentage, the higher values indicate situations of low efficiency. That may be a performance indicator of blood collect done by the institution. A high loss percentage represents a high variable cost. The main costs involved are related to the blood pack, serology test, carried-out on samples from donation, donors' management, which includes printing of donors ID card and issuance a letter informing the serology result. There is also the possible cost of a second serology test, in case the first one indicates the occurrence of determinate problems. In this case, the second exam is obligatory and is under the blood bank responsibility to afford for the cost of it.

Source: Information supplied by Santa Casa's Blood Bank

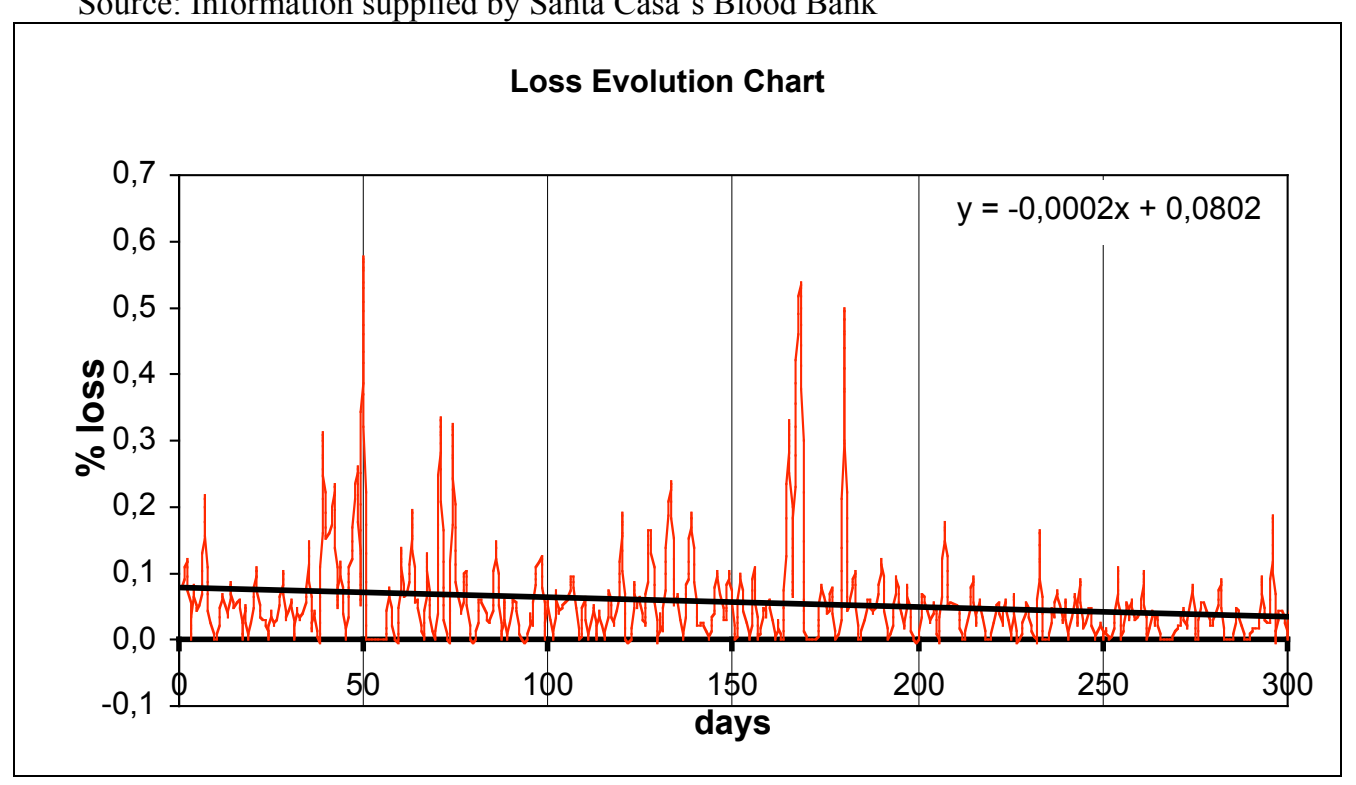

Chart 1 - Loss Evolution from January to October 2004 
Upon analysing the, one can note that the level of loss evolution shows a negative tendency. That may even be detected visually, but it's corroborated by the linear coefficient of the estimated tendency line based on this series. The tendency line is linear, and is presented on the series and its equation is indicated on the upper part of the Chart 1

One can also note that the evolution loss presents strong oscillation behaviour, yet with a not large dispersion, bar some exceptions. Those values are outliers representing anomalies in the series, reaching in these points, nearly $60 \%$ of the total collected.

It was discovered that those periods of great loss are associated to collection campaigns and other related initiatives towards donor's contributions, in other words, when there is a larger number of occasional donors. The collectors' team unanimously considered that the material collected from occasional donors presents a higher level of problems than the material from regular donors. There is also the habit of people donating just for submitting their blood to a free laboratory test. In financial terms, there is a loss of profitability, although the campaigns and initiatives are, sometimes, instrumental for the stock maintenance.

It can be further detected through the present analysis that, the best way to reduce the loss impact is to invest on regular donors, since statistically the occasional donors present bigger chances of having their blood with positive serology.
The negative declivity detected in the loss historical series, and identified by the tendency line, is explained by the effective pursuance of regular donors. They are the main target of Santa Casa's blood bank.

In general terms, the analysis of the historic efficiency levels indicates that to avoid high expenditure originated by losses, the industry should focus on regular donors.

Another important factor is that campaigns and initiatives should be carried-out only when the stock reaches dire levels. Consequently, the costs resulted by the undesirable losses by laboratorial restrictions will be compensated by the need of the stock replenishment.

\subsection{Stock Forecasting}

One blood component was taken into account for the application of forecasting methods. The managing problem of twenty four SKUs can be solved by studying just one of these unities, replicating the chosen methodology for the other twenty three. The Platelet Concentrate was chosen for two reasons: the demand is not that high and second once they present a low lifetime around 3 to 5 days. In general terms, the periods of low availability of this item are frequent. Managing its stock is one of the biggest challenges of a blood bank. The study of the Platelet Concentrate can be seen on the Chart 2.

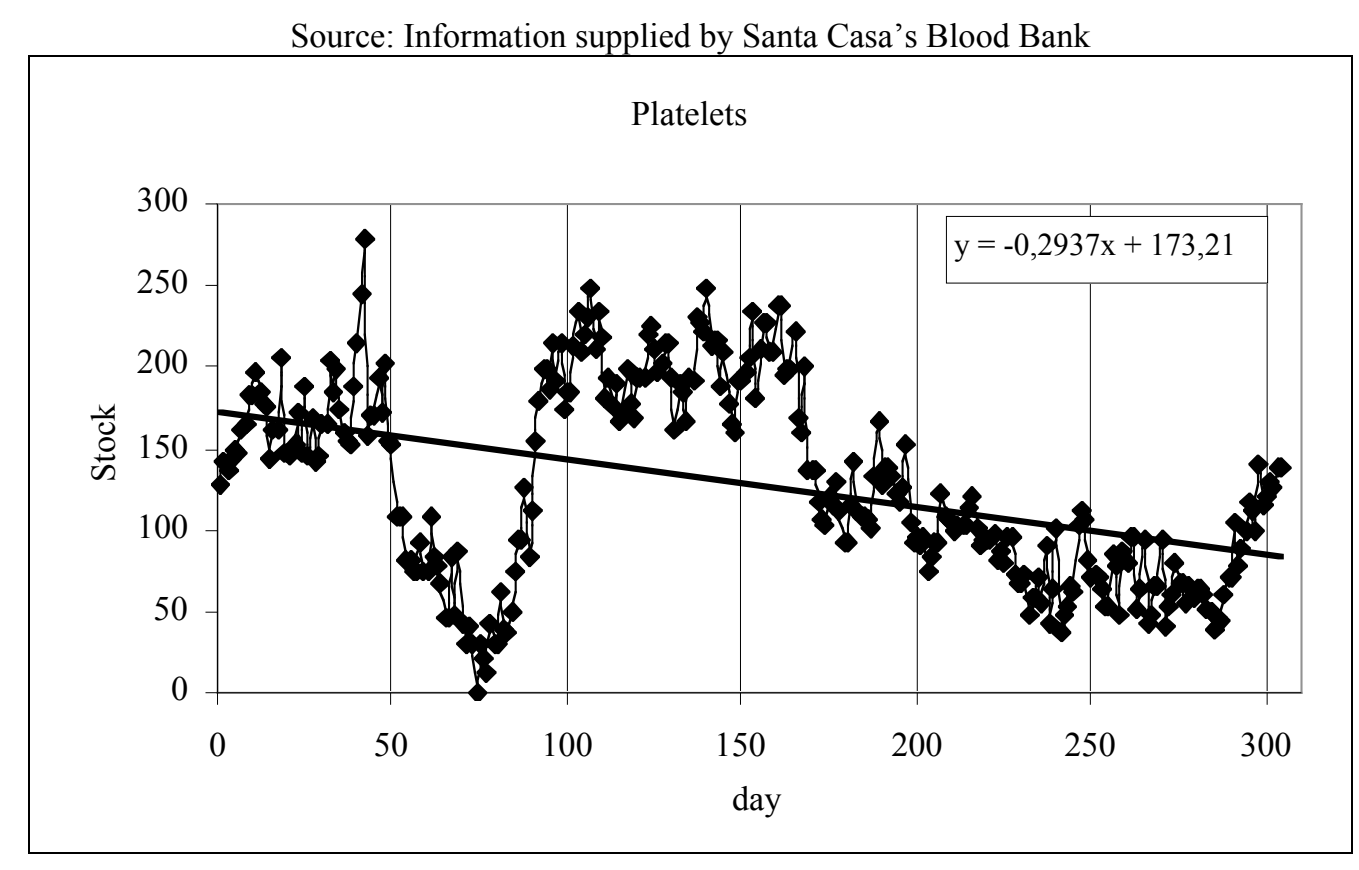

Chart 2 - Balance of Platelets

In just one moment of the referred period of analysis there was a stock out. On the other moments the stock remained in critical levels. That can be easily perceived through the historical analysis, i.e. the fall of stock level is not sudden: it occurs in a gradual manner. The quick identification of those moments is instrumental for a good inventory control. Upon previewing a very low level condition, contingency plans might be adopted, i.e. 
last minute campaigns to gather donors. For that purpose, prevision and stock management models have to be employed to follow-up the available level of products.

To forecast the stock of Platelet Concentrate, several quantitative methods were tested such as Moving Average, Exponential Adjustment, HoltWinters, and Regression. Those methodologies are described by Winston \& Albright [14]. We present the analysis done through the proposed classification by Corrêa \& Corrêa [3] scheme.

\subsubsection{Intrinsic Methods}

The Intrinsic Methods employed were the Moving Average and Exponential Adjustment. It's advisable to note that the employment of regression models together with Moving Average model do not transform them into Extrinsic Models, once in these cases only the time was used as dependent variable.
To illustrate the series we established three moving centred averages: MA3, MA4 and MA5. The MA3 was the adopted model, for it presented a smaller quadric error. The graph can be seen on Chart 3. Its equation is shown on the upper part of the graph. The low determination coefficient value $\mathrm{R}^{2}$ depicts the model low adequacy to the data.

The Exponential Adjustment model present a component called constant of adjustment. The choice of this parameter may be done through an optimisation tool, seeking the minimisation of some expression for the model's total error. We employed the totals of the errors squares to estimate that constant, which was 0.9 values.

On Chart 4, it's possible to note that the model, visually, is as good as the one obtained by the moving average. However, the Adjustment Exponential Model allows us to predict the next value without the use of an exogenous tool, which makes the model more adequate for a prevision.

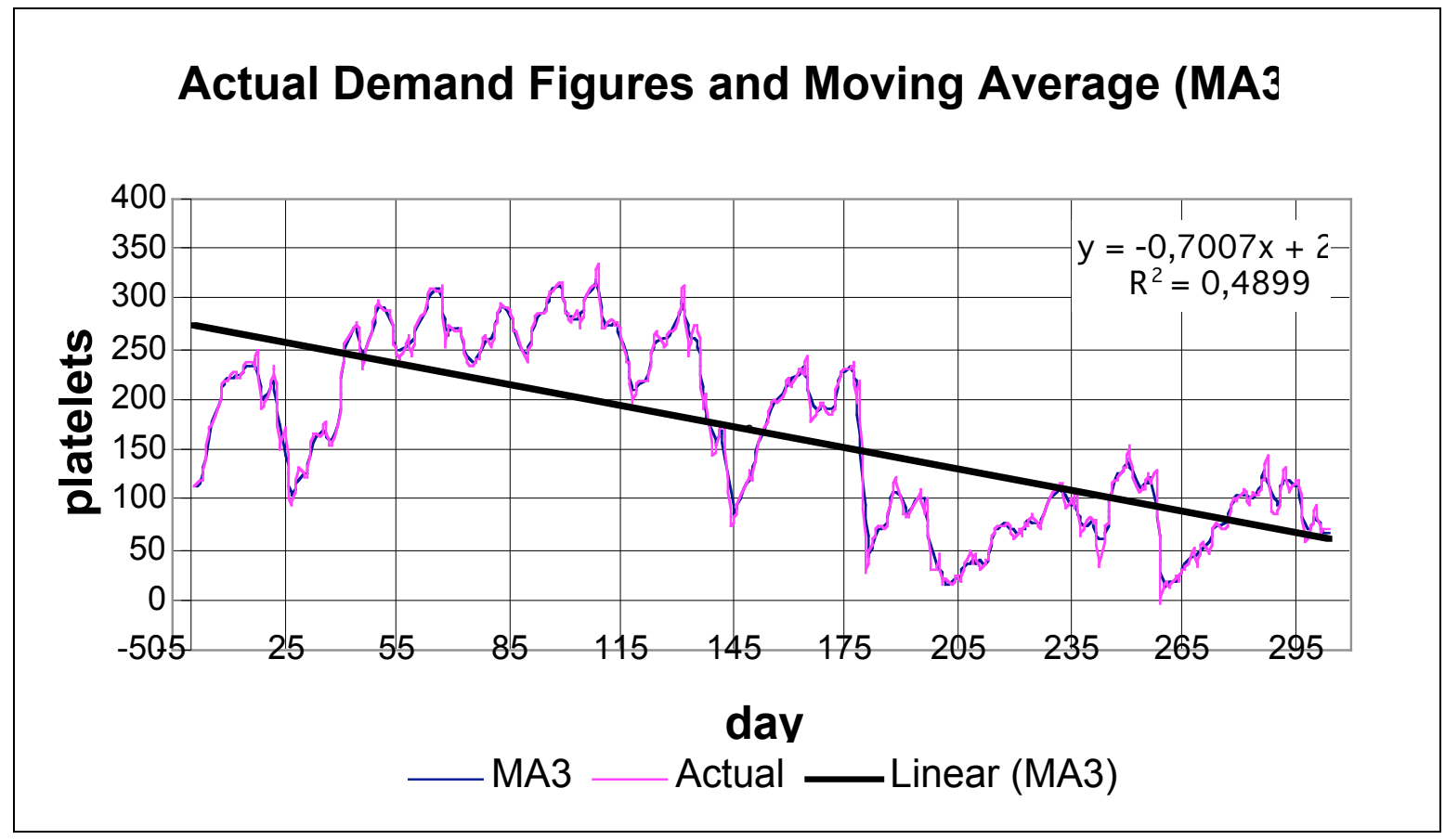

Chart 3 - Actual Demand Figures vis-à-vis Moving Average (MA3) 


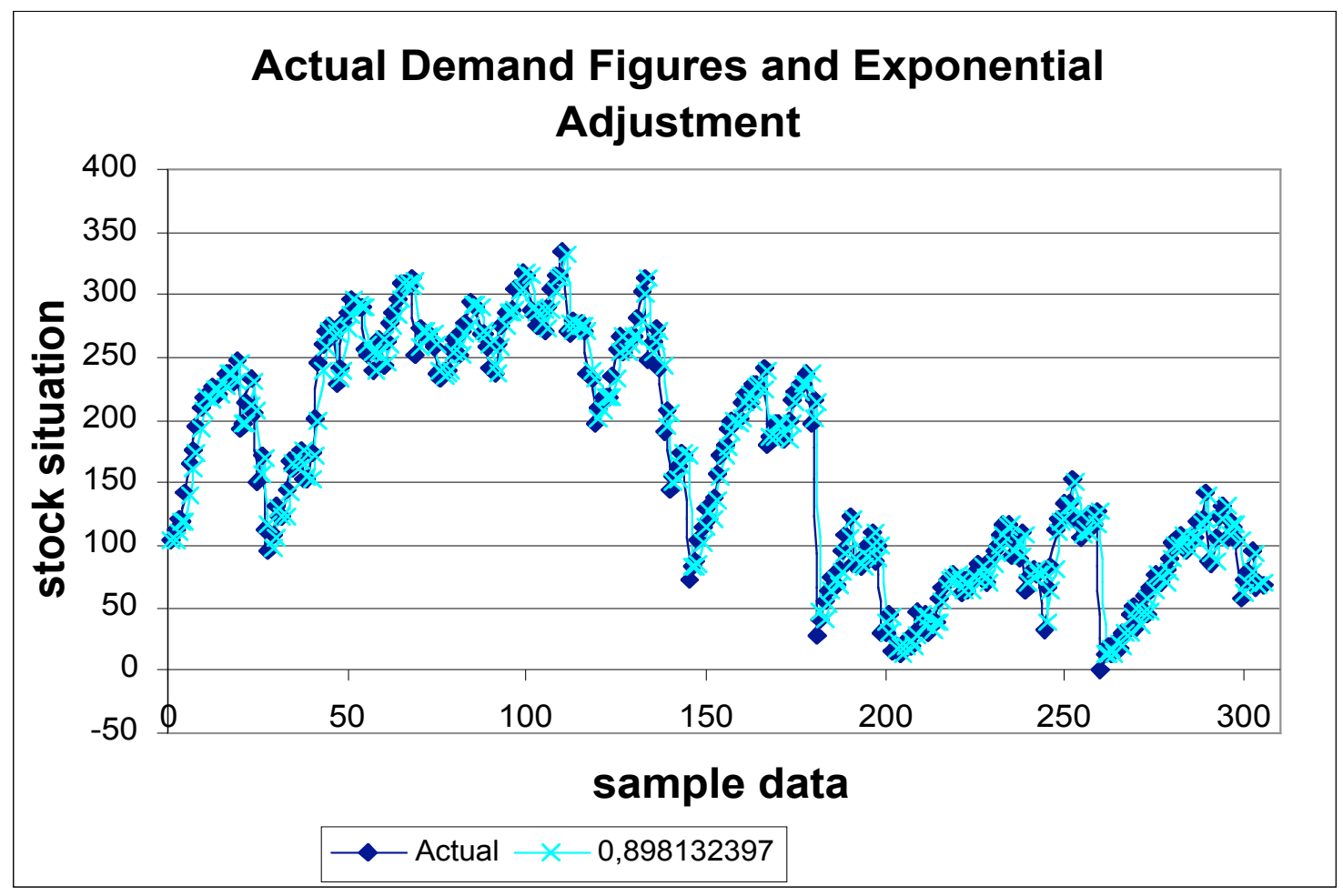

Chart 4 - Actual Demand Figures vis-à-vis Exponential Adjustment

More sophisticated models that consider the existence of tendency and seasonality in the data, like the Holtwinters Exponential Adjustment models, or the Moving Average model considering Seasonal Indices, were unsuccessfully tested. The performance measures, mainly the error rate, presented worse performance when compared to simpler models.

\subsubsection{Extrinsic Models}

The Regression models were estimated by employing minimum squares method, executed in the Excel

Spreadsheet. Theoretical details on this estimation method can be seen in Draper \& Smith [4], Mendenhal \& Sincich [8] and Sincich [13].
A multiple regression model was employed in the attempt to follow up the series. Explanatory variables were used in the attempt to codify the seasonality and tendency.

The seasonality was defined through various binary variables called dummies codified for the model. The aim was to perceive the weekly seasonality by codifying the week day in 7 levels and the monthly seasonality by codifying the month day in 31 levels. To clarify the procedure, see Illustration 2 that defines the employed dummies variables.

The results of multivariate regression model's employment are shown in Table 2.

In general terms, all the analysed regression models present a low adjustment, vis-à-vis the high error rate, as it may be seen through the determination coefficient. 


\begin{tabular}{|l} 
D1 $\quad\left[\begin{array}{l}1 \text { if it is monday } \\
0 \text { if it is not monday }\end{array}\right.$ \\
D2 $\quad\left[\begin{array}{l}1 \text { if it is tuesday } \\
0 \text { if it is not tuesday }\end{array}\right.$ \\
D3 $\quad\left[\begin{array}{l}1 \text { if it is wednesday } \\
0 \text { if it is not wednesday }\end{array} \quad\right.$ D6 it is not thursday \\
0 if it is not friday \\
0 if it is not saturday
\end{tabular}

\begin{tabular}{|c|c|c|c|c|c|c|}
\hline \multicolumn{7}{|l|}{ 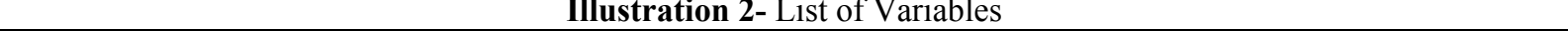 } \\
\hline \multicolumn{7}{|c|}{ SUMMARY OUTPUT } \\
\hline \multicolumn{2}{|c|}{ Regression Statistics } & & & & & \\
\hline Multiple R & 0,683346351 & & & & & \\
\hline R Square & 0,466962236 & & & & & \\
\hline Adj. R Square & 0,454399056 & & & & & \\
\hline Standard Error & 65,88284093 & & & & & \\
\hline Observations & 305 & & & & & \\
\hline \multicolumn{7}{|l|}{ ANOVA } \\
\hline & $D f$ & $S S$ & $M S$ & $F$ & Significance $F$ & \\
\hline Regression & 7 & 1129340,41 & 161334,34 & 37,169 & $3,35366 \mathrm{E}-37$ & \\
\hline Residual & 297 & 1289142,97 & 4340,55 & & & \\
\hline Total & 304 & 2418483,38 & & & & \\
\hline & Coefficients & Standard Error & $t$ Stat & $P$-value & Lower 95\% & Upper 95\% \\
\hline Intercept & 268,1070 & 11,9363 & 22,4614 & $5,47385 \mathrm{E}-66$ & 244,6165 & 291,5975 \\
\hline OBS & $-0,6899$ & 0,0428 & $-16,1009$ & $2,30277 \mathrm{E}-42$ & $-0,7742$ & $-0,6056$ \\
\hline D1 & 4,2198 & 14,1281 & 0,2987 & 0,76538953 & $-23,5840$ & 32,0237 \\
\hline D2 & $-1,8233$ & 14,1278 & $-0,1291$ & 0,89740113 & $-29,6266$ & 25,9801 \\
\hline D3 & 4,3604 & 14,1277 & 0,3086 & 0,757809134 & $-23,4427$ & 32,1635 \\
\hline D4 & 0,1911 & 14,0469 & 0,0136 & 0,989154976 & $-27,4529$ & 27,8351 \\
\hline D5 & 8,4840 & 14,0465 & 0,6040 & 0,546311849 & $-19,1594$ & 36,1273 \\
\hline D6 & 6,9919 & 14,0463 & 0,4978 & 0,619011441 & $-20,6510$ & 34,6348 \\
\hline
\end{tabular}

Table 2 - Multiple regression models for stock estimation

\subsubsection{Analysis of Results}

The low adjustment of the prevision models based on the temporal series decomposition is a direct consequence of the fact that the demand, and mainly the supply, presents a strong fortuitous component. The modelling attempts, based on tendency and seasonality isolation, are frustrated, once those components are smaller in comparison with the one that cannot be isolated.

The model that better adapted to the series was the simple exponential adjustment, which is not specific for any data characteristic, which probably was determining. The selection criterion for that was the accuracy, measured through a function of total quadric error.

\subsection{Employment of Forecast Results}

The several methods developed were applied to forecast and identify the stock situation in November $1^{\text {st }}, 2004$. Various different previsions were done to generate more result safety and increase the assurance level. Every method led to a similar result to the 306th observation. All models carried-out predictions for levels of Platelet Concentrate between 55 and 65 .

This range of values is well bellow the tendency balance line of the item, which leads to a strong alert of a low balance. The result surprised the 
managing director responsible for the blood bank, as before there weren't any objective form of finding the expected future balance. That information was highly relevant. Based on that, immediately several regular donors were summed up, and with that procedure the balance was normalised again. From that application, it was perceived the possibility of automating the stock analysing process, in a form that an alert could be generated, recommending the carry-out of some sort of campaign for each historic moment.

\section{Conclusions}

There are many similar characteristics between the inventory of a blood bank and the stock of any other conventional company. In both kinds of activities, there is a team responsible for managing the products disposal, and various sorts of stockpiling products. However, there is a great difference: there cannot be stock out in a blood bank, since third party lives depend on blood components.

By employing various forecasting models at Santa Casa, the stock manager could collect information that would lead to a shortage in the blood stock before it occurred. Therefore the doctors were able to initiate the replenishing strategies, and succeeded in maintaining the stocks at acceptable inventory levels.

However, a fundamental initiative is to maintain a group of regular donors, as they represent less cost for the blood bank, since they statistically have a smaller chance to be serum positive for blood transmitted diseases.

The graph of Platelet stock evolution, on the Chart 2, points towards a condition of negative tendency, indicates a long-term fall in terms of products availability. That happens since the market demands more and more blood components. A possible change, in terms of demand could result from blood rationalisation, arisen by the use of more advanced surgical methods with fewer cuts, less bleeding and, consequently, smaller number of transfusions. For awhile, both blood demands by emergency patients have been kept constant and, patients with surgical procedures with a strong positive tendency.

Considering a research carried-out through Saúde Business Web portal, circa $50 \%$ of participants indicate the lack of professionals managing the main problem faced by private hospitals [12]. The research confirms that both the health industry and other market segments are getting modernised. This an excellent niche to be exploited by management professionals, even if they have no health segment background.

The automation process of blood stock control at the examined blood bank has just begun. Santa Casa intend to develop a system that can, besides automatically trigger alarms, analyse the type of donation campaign best recommended for the particular stock situation moment. The said system will be a great step forward in automation process of blood stock; however that will only be possible with the introduction of a new culture in the institution and after some paradigms are broken.

Other studies should be carried-out to improve models of performance, considering the effects of stock losses by perish ability. Such an effect could cause a sudden stock shortage once it is not well monitored. Another effect that could be included is linked to some abnormal moments in the year like, holidays, when, normally, there is an increase of blood demand pointing out a seasonality tendency. Those should be differentiated from the normal periods by the employment of binary variables.

\section{References}

[1] ASHLEY, Patrícia Almeida (coord.). Ética e Responsabilidade Social nos Negócios. 2. ed. São Paulo: Saraiva, 2005. 340 p.

[2] CÔRREA, Henrique L., GIANESI, Irineu G. N. e CAON, Mario. Planejamento, Programa e Controle da Produção. 4. ed. SP: Ed. Atlas, 2001.

[3] CORRÊA, Henrique L. e CORRÊA, Carlos A. Administração de produção e operações: manufatura e serviços: uma abordagem estratégica. 2. ed. São Paulo: Atlas, 2006.

[4] DRAPER, N. R. e SMITH Jr., H. Applied Regression Analysis. New York, EUA: John Wiley \& Sons, 1966.

[5] FGV. Fundação Getúlio Vargas. Available in: $<$ http://www2.fgv.br/fgvmanagement/> Accessed on: 04/20/2005.

[6] GOODWIN, Paul e WRIGHT, George. Decision analysis for management judgment. 3. ed. John Wiley \& Sons. 2004. $492 \mathrm{p}$.

[7] LABONTE, Ronald. Health, Globalization and Sustainable Development. World Health Organization Meeting "Making Health Central to Sustainable Development", Oslo, Norway, 2001.

[8] MENDENHALL, William e SINCICH, Terry. A second course in business statistics: regression analysis. 4. Ed. New York: Dellen Publishing, 1993. 859p.

[9] OSC. OSC Home page. Available in: $<$ http://www.osc.state.nc.us/sigdocs/sig_docs/s igStock_Keeping_Unit_SKU.html $>$ Accessed on: $04 / 23 / 2005$.

[10] RAZOUK, Fernanda H. e REICHE, Edna M. $\mathrm{V}$. Characterization, production and indication of the principal blood 
components. Rev. Bras. Hematol. Hemoter. vol.26 no.2 São José do Rio Preto 2004. Also a $\mathrm{v}$ a $\mathrm{i} 1 \mathrm{a}$ b 1 e i $\mathrm{n}$ : $<$ http://www.scielo.br/pdf/rbhh/v26n2/v26n2a 11.pdf> Accessed on: 04/20/2005. 
[11] SANTA CASA. Santa Casa da

M i s e ri córdia . Disponível em:

$<$ http://openlink.br.inter.net/santacasa/hospital.

htm> Accessed on: 04/10/2005.

[12] SAUDEBUSINESS. Sáude Business Web.

Available in:

$<\mathrm{http}$ ://www.saudebusinessweb.com.br/enquete.vx lpub?questionID=535> Accessed on: 04/23/2005.

[13] SINCICH, T., Business Statistics by

Example. Upper Saddle River, New Jersey:

Prentice-Hall, Inc, 1996.

[14] WINSTON, Wayne L. e ALBRIGHT, S.

Christian. Practical Management Science:

spreadsheet modeling and applications. 2. ed.

South-Western College Pub, 2004. 953 p. 